75 years of Agricultural University - Plovdiv

JUBILEE SCIENTIFIC INTERNATIONAL

CONFERENCE Plovdiv 26-28 November 2020
PERSPECTIVES ON AGRICULTURAL SCIENCE AND INNOVATIONS FOR SUSTAINABLE FOOD SYSTEMS

\title{
DOI: 10.22620 /agrisci.2021.30.006 \\ DEPENDENCIES IN THE DEVELOPMENT OF POULTRY FARMING IN SOME BALKAN COUNTRIES
}

\section{Delyana Dimova}

\author{
Agricultural University - Plovdiv
}

E-mail: delydimova@abv.bg

\begin{abstract}
Information concerning poultry farming (chickens, ducks, geese and guinea fowls) is the object of study in the current paper. It has been extracted from the website of the Food and Agriculture Organization of the United Nations. The obtained data about the four Balkan countries (Bulgaria, Greece, Romania and Albania) have been saved in a separate Excel file. Subsequently, they have been processed and evaluated. The surveyed period includes 58-year time interval from 1961 to 2018.

The article presents the dependencies in the development of poultry farming in the listed countries for the indicated period. A comparative analysis and an analysis of variance have been applied to the considered data. The examined information has also been summarized and presented mainly in graphical form.

The results of the analysis showed the relevant time intervals in which a continuous growth, as well as a significant decline of the studied indicators (number of chickens, number of ducks, number of geese and guinea fowls) was established for each of these four Balkan countries.

The statistical assessment of the number of chickens in the examined countries formed three groups with statistically significant differences. Data for Albania were excluded from the evaluation of the other two indicators because the provided information about them was for the period from 1994 to 2011.
\end{abstract}

Key words: data analysis, assessment, poultry farming, Balkan countries.

\section{INTRODUCTION}

The most intensive livestock sector is poultry farming. Since 2007 not only the internal market, but, to a large extent, factors relating to the requirements of the common European market for the application of new technologies, prices and quality, food safety, animal welfare, the protection of the environment have been important for its development (Kostadinova, 2017).

Poultry farming is one of the best tools available for an integrated rural development and socio-economic transformation of small entrepreneurs. No other branch of agriculture/animal husbandry made such a growth in development as achieved by the poultry industry (Mathialagan, Senthilkumar, 2012).

Over the last few years, poultry farming has been undergoing a process of farm reconstruction and modernization, as well as establishing systems that ensure welfare in poultry farming, complying with the EU requirements. This leads to a large extent to changes in the production and product structure of the sector (Kostadinova, 2017).

Data on poultry farming (chickens, ducks, geese and guinea fowls) are the object of study in this work.

The aim of the article is to present the dependencies in the development of the poultry farming in four Balkan countries (Bulgaria, Greece, Romania and Albania) for the time 
75 years of Agricultural University - Plovdiv JUBILEE SCIENTIFIC INTERNATIONAL CONFERENCE Plovdiv 26-28 November 2020
PERSPECTIVES ON AGRICULTURAL SCIENCE AND INNOVATIONS FOR SUSTAINABLE FOOD SYSTEMS interval from 1961 to 2018.

\section{MATERIALS AND METHODS}

Information about the referred countries is published on the website of the Food and Agriculture Organization of the United Nations (www.fao.org/faostat/en). FAO's Food and agriculture database provides free access to food and agriculture statistics for over 245 countries and territories and covers all FAO regional grouping from 1961 to the most recent year available (www.fao.org/economic/ess/ess home/ess-about/data-collection/en/).

Data on poultry farming (chickens, ducks, geese and guinea fowls) have been extracted from the website of this organization (http://www.fao.org/faostat/en/\#data/QA). The obtained information about the listed Balkan countries has been saved in an Excel file. The surveyed period includes 58-year time interval. The presented data about the poultry farming have been processed and analyzed. The capabilities of the Microsoft Excel program (Mihaylov, 2016, Levine et al., 2016) and software package R Commander (NguyenFeng, Stellmack, 2016) have been used for this purpose. Working with lists of data and applying different filters, users could display the relevant subsets from the studied elements (Georgieva and Blagoeva, 2019, Lozanova et al., 2001).

The comparative analysis and analysis of variance (Sawyer, 2009, Tukey, 1949) have been used in this work to investigate the data related to the poultry farming in the considered four countries. The examined information has also been summarized and the relevant results have been presented mainly in graphical form.

\section{RESULTS AND DISCUSSION}

The indicated data about poultry farming have been surveyed in the years between 1961 and 2018. They have been organized and stored in an Excel file. Using certain filters, the following information is obtained and visualized:

- Data on the number of chickens in the listed countries for the chosen years;

- Number of ducks in the relevant countries for the selected interval;

- Number of geese and guinea fowls in the considered countries for the indicated years;

It should be noted that there are cases in which the user could request studying the data only for a part of the listed objects.

The information about one examined object for two of the countries during 3-year time period is presented on Fig. 1. Quite naturally, the users can choose other subsets from the elements in a similar way.

\begin{tabular}{|c|c|c|c|c|c|c|}
\hline 4 & A & B & C & D & $E$ & $\mathrm{~F}$ \\
\hline 1 & Area $\sqrt{\nabla}$ & Elemer & Item & Year $\quad \nabla$ & Unit & $\mathrm{Val} \sqrt{\mathrm{V}}$ \\
\hline 60 & Bulgaria & Stocks & Chickens & 1961 & $\begin{array}{l}1000 \\
\text { Head }\end{array}$ & 22241 \\
\hline 61 & Bulgaria & Stocks & Chickens & 1962 & $\begin{array}{l}1000 \\
\text { Head }\end{array}$ & 21574 \\
\hline 62 & Bulgaria & Stocks & Chickens & 1963 & $\begin{array}{l}1000 \\
\text { Head }\end{array}$ & 19845 \\
\hline 118 & Greece & Stocks & Chickens & 1961 & $\begin{array}{l}1000 \\
\text { Head }\end{array}$ & 14337 \\
\hline 119 & Greece & Stocks & Chickens & 1962 & $\begin{array}{l}1000 \\
\text { Head }\end{array}$ & 15030 \\
\hline 120 & Greece & Stocks & Chickens & 1963 & $\begin{array}{l}1000 \\
\text { Head }\end{array}$ & 17161 \\
\hline
\end{tabular}

Fig. 1. Visualization of data for two of the surveyed Balkan countries in the years between 1961 and 1963

Source: Food and Agriculture Organization of the United Nations, FAOSTAT

Specially, the data concerning the number of chickens for each of the presented four Balkan countries were analyzed and compared. As a result of this study, the following dependencies were observed (Fig. 2):

- The period from 1961 to 1989 is characterized by an almost continuous growth in the number of chickens in Albania. The only 
75 years of Agricultural University - Plovdiv JUBILEE SCIENTIFIC INTERNATIONAL CONFERENCE Plovdiv 26-28 November 2020
PERSPECTIVES ON AGRICULTURAL SCIENCE AND INNOVATIONS FOR SUSTAINABLE FOOD SYSTEMS exceptions were established in 1963, 1965, 1967, 1968 and 1988, where the calculated decline was not great. At the end of the indicated 29-year interval, the increase of this indicator is over 3,5 times. A similar situation is obtained about these investigated data for Bulgaria and Romania. Approximately the same dependence in the number of chickens is established during this period. It should be noted that in this case for 9 non-consecutive years $(1962-1963,1965-$ 1966, 1969, 1975, 1979, 1982, 1986) a certain decline of the indicator was registered for Bulgaria, while for Romania the respective reduction was in 1963, 1972, 1978, 1980 and 1986. As a whole, at the end of this period the increase of the considered indicator is about 2 times for Bulgaria and over 3,3 times for Romania.
- The decline of the number of chickens is significant for the time interval 1990-2000 in Romania. It is more than 1,7 times. A similar dependence was established for the studied data about Bulgaria in the indicated period. In this case the decrease of the surveyed indicator is over 2 times. A process of gradual growth of this variable has been observed in the interval 2001-2005 for Romania and 2001-2004 for Bulgaria, as can be seen from the diagram presented on Fig. 2. The periods alternate over the next 12 years in which the indicator values decline or increase, respectively. In the last year of the interval (2018) its decline is more than 1,1 times for Romania and about 1,3 times for Bulgaria.

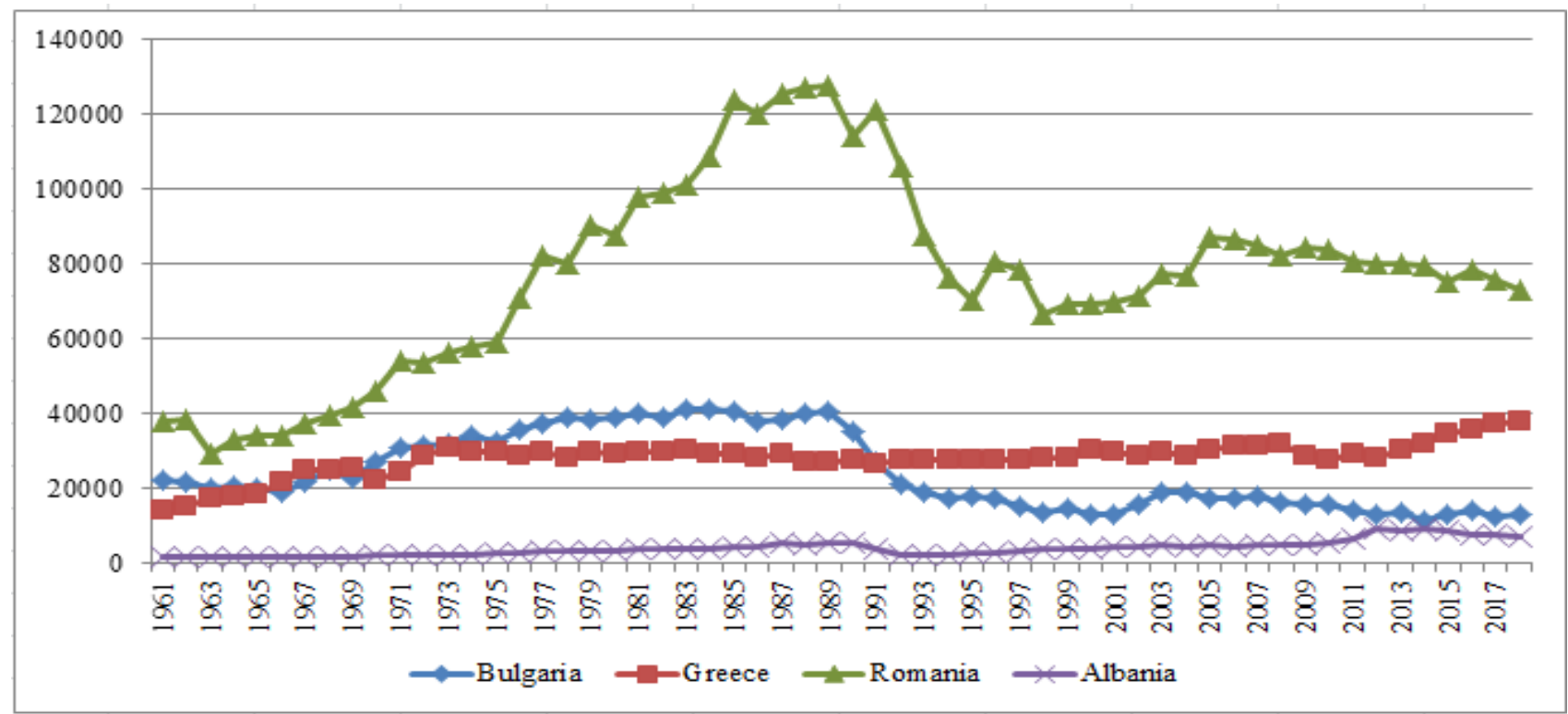

Fig. 2. Change of the number of chickens in the studied period, (thousands)

Source: Food and Agriculture Organization of the United Nations, FAOSTAT

- A quite big decline in the number of chickens in Albania for a significant small period from 1990 to 1993 is visualized on Fig. 2. In this case, it is over 2,3 times. The interval 1994-2010 is characterized with a steady increase of the indicator values, while this process is more intensive in 2011-2014. It should be noted that, a quite small decrease of this variable was observed in 2004, 2009 and 2013. The highest value in the number of chickens in Albania was registered in 2012. Over the next four years (from 2015 to 2018) the values of this variable decreased steadily, with an exception in 2017. 
75 years of Agricultural University - Plovdiv JUBILEE SCIENTIFIC INTERNATIONAL CONFERENCE Plovdiv 26-28 November 2020
PERSPECTIVES ON AGRICULTURAL SCIENCE AND INNOVATIONS FOR SUSTAINABLE FOOD SYSTEMS
- A little different is the situation for Greece. The more intensive growth of the number of chickens was established in the period 1961-1973. It was about 2,1 times. Over the next 16-years (1974-1989) the values of the examined indicator marked a certain decline in comparison with 1973. An almost constant increase in the number of chickens was observed for the period 1990-2008. The calculations showed that there was one reduction in the 4-year interval from 2009 to 2012. An interesting fact could be noted. This examined indicator increased at a significantly faster pace during the period 2013-2018.

Information about the number of ducks in the four Balkan countries (Bulgaria, Greece, Romania and Albania) was studied separately (Fig. 3.). The analysis of the data for Romania showed that there are years in which the indicator decreased and then increased or vice versa. Only the time intervals 1963-1968 and
1983-1989 are characterized with a continuous growth of the number of ducks. In the years between 1990 and 1999, the reverse process was observed. A decline of about 14,9 \% was established. The values of this variable remained almost the same in the interval from 2000 to 2010 . The change of the number of ducks in Romania for the period 2011-2018 is insignificant, while a certain increase has been observed in the last year. The highest and the lowest value of the studied indicator were registered in 1989 and 1969, respectively. The number of ducks in Greece decreased constantly in the interval from 1961 to 1989 (Fig.3.). The calculated decline is about 2,5 times. The same dependence for the number of ducks in the period 1991-2017 was obtained. But in this case the reduction is over 4,5 times. Another fact is of interest. During 1990, as compared to 1989, the studied variable grew significantly by about $33,70 \%$.

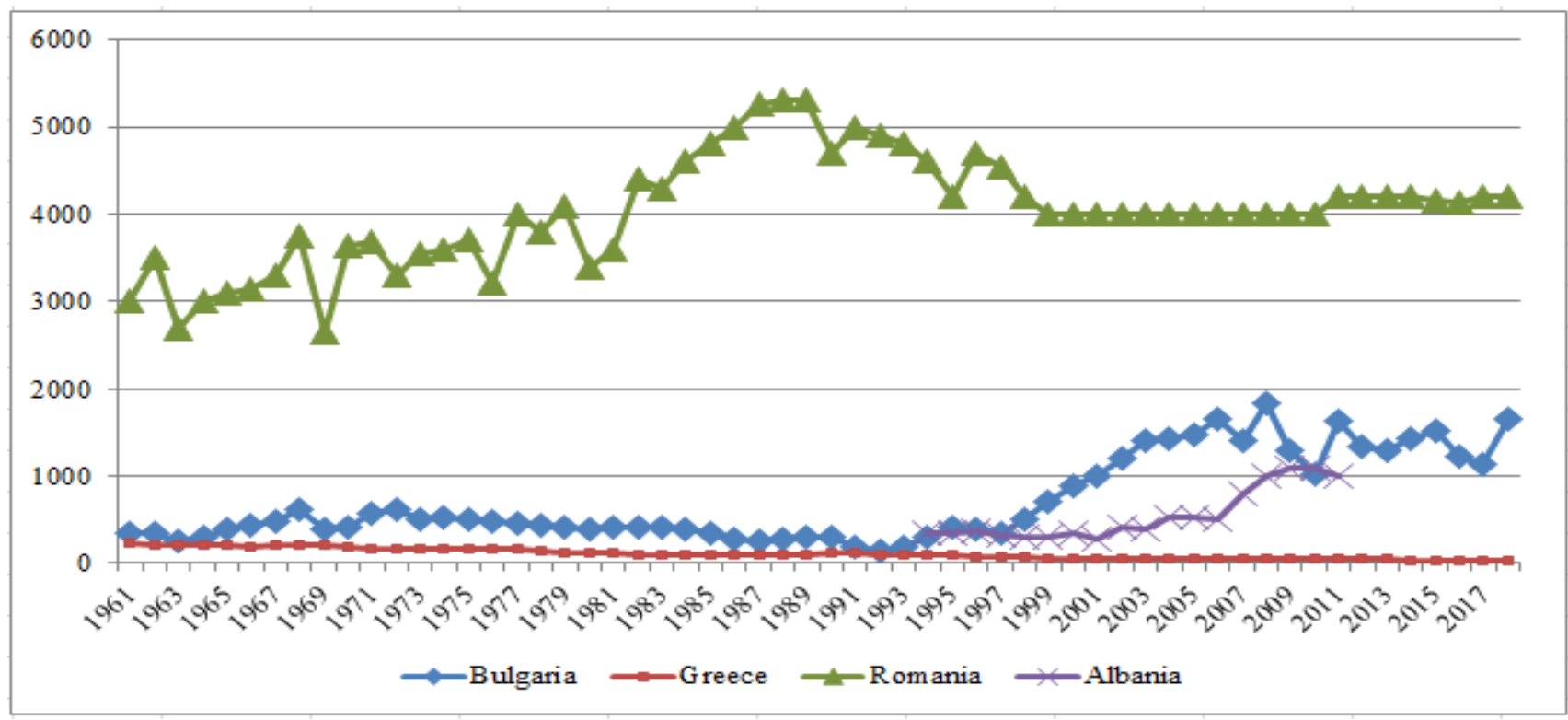

Fig. 3. Graphic analysis of the number of ducks in 1961-2018, (thousands)

Source: Food and Agriculture Organization of the United Nations, FAOSTAT

The current survey shows that the number of duck in Bulgaria decreased more than 2 times in the period 1970-1992. Only for five consecutive years (1964-1968) a certain growth of the indicator was registered. Another interesting fact should be noted. The examined values of this variable increased significantly for the next 16-year time interval (1993-2008). In 
75 years of Agricultural University - Plovdiv JUBILEE SCIENTIFIC INTERNATIONAL CONFERENCE Plovdiv 26-28 November 2020
PERSPECTIVES ON AGRICULTURAL SCIENCE AND INNOVATIONS FOR SUSTAINABLE FOOD SYSTEMS this case the number of ducks grew over 9 times. The indicator values changed quite dynamically in the last 10 years of the considered period.

The published information on the website of the mentioned organization about the number of ducks in Albania includes the period 1994-2011.
Generally speaking a process of a gradual growth of the values of the indicated variable has been established. It should be noted that, a small decline was registered in 1997-1998, 2001, 2003, 2006 and 2011.


Fig. 4. Studied data about the number of geese and guinea fowls, (thousands)

Source: Food and Agriculture Organization of the United Nations, FAOSTAT

The investigated data on the number of geese and guinea fowls in Greece, Bulgaria and Romania were also compared and analyzed for 58-year time interval. Two periods (1964-1968 and 2000-2004) were formed in which the number of geese and guinea fowls in Bulgaria increased steadily. Each of them contains five consecutive years (Fig. 4). Overall, this studied variable declined significantly during 19691999 in the indicated country. The same 
75 years of Agricultural University - Plovdiv JUBILEE SCIENTIFIC INTERNATIONAL CONFERENCE Plovdiv 26-28 November 2020
PERSPECTIVES ON AGRICULTURAL SCIENCE AND INNOVATIONS FOR SUSTAINABLE FOOD SYSTEMS dependence for the examined indictor is observed for the period from 2005 to 2018 . The calculations showed that the indicator values increased slightly in 1975-1977, 1982-1983, 1989, 1994 and 2007.

The evaluation of the data on the number of geese and guinea fowls in Greece showed a decreasing tendency for the years between 1961 and 1994. The decline is more than 2,7 times at the end of the examined time interval. The values of the considered variable remained almost the same in 1995-2012. A process of reduction of the indicator values was observed again in 2013-2016. Quite naturally, the lowest value of the number of geese and guinea fowls for 58-year time interval was registered in 2016. The calculated growth of this variable is about $10 \%$ during the last two years from the surveyed period.

The situation is quite different for the examined information concerning the number of geese and guinea fowls in Romania during 1961-1989. In the case, a clearly-expressed increasing tendency was observed (Fig. 4.). It should be noted that, the studied indicator increased more than 2,6 times for the indicated period. A certain decline of the values of the considered variable was established for the years 1990-2004. The number of geese and guinea fowls has been growing steadily since 2005, and the values of the indicators in 2018 are very close to those in 1989.

The presented data on Albania from the website of the Food and Agriculture Organization are from the period 1994 to 2011. Then the survey includes 18-year time interval. Conditionally, this period could be divided in two intervals. The first of them includes 19942006. The lowest value of the number of geese and guinea fowls was recorded in 1999. Compared to the year 1998, the indicator decreased by $2,44 \%$. During this 13 -year period, the highest value of the examined variable was observed in 2005 . The second interval contains the years 2007-2011. The growth of the number of geese and guinea fowls was significant in 2007-2008. In the case, it was about 2,7 times. The indicator values remained the same in 20082011 (Fig. 4.).

Table 1. Presentation of the results for the considered countries

\begin{tabular}{|c|l|l|}
\hline Countries & \multicolumn{2}{|c|}{$\begin{array}{c}\text { Assessment of the number } \\
\text { of chickens }\end{array}$} \\
\hline Romania & 76928 & a \\
\hline Greece & 27949 & b \\
\hline Bulgaria & 24355 & b \\
\hline Albania & 4054 & c \\
\hline
\end{tabular}

Means with the same letter are not significantly different.

Source: Own calculations on the basis of data from FAO, FAOSTAT

The analysis of variance (Anova) has been used for the studied data related to the examined Balkan countries. The presented results showed that there were statistically significant differences $(\mathrm{P}$-value $<0.05)$ between the number of the chickens in these four countries. According to Tukey's range test, the obtained information from the assessment is visualized in Table 1 . The following three groups are formed:

- The highest number of chickens for the considered time interval is in Romania;

- Two countries follow the indicated above country by the surveyed indicator. These are Bulgaria and Greece;

- The lowest number of chickens is observed in Albania.

The analysis of variance (Anova) and Tukey's range test have also been applied to the data on the number of ducks in the surveyed countries - Bulgaria, Greece, and Romania. The results of the assessment are displayed in Table 2 . In this case three groups with statistically significant differences are presented: 
75 years of Agricultural University - Plovdiv JUBILEE SCIENTIFIC INTERNATIONAL CONFERENCE Plovdiv 26-28 November 2020
PERSPECTIVES ON AGRICULTURAL SCIENCE AND INNOVATIONS FOR SUSTAINABLE FOOD SYSTEMS
- The highest number of ducks in the studied period is in Romania;

- $\quad$ Greece is included in a separate group;

- The lowest number of ducks for the examined time interval is in Bulgaria.

Table 2. Assessment of the studied data about the number of ducks

\begin{tabular}{|c|l|l|}
\hline Countries & \multicolumn{2}{|c|}{$\begin{array}{c}\text { Assessment of the number } \\
\text { of ducks }\end{array}$} \\
\hline Romania & 4031 & a \\
\hline Greece & 714 & b \\
\hline Bulgaria & 113 & c \\
\hline
\end{tabular}

Means with the same letter are not significantly different.

Source: Own calculations on the basis of data from FAO, FAOSTAT

A similar situation has also been obtained from the evaluation about the number of geese and guinea fowls in the listed above countries. The results are visualized in Table 3 .

The data for Albania have been excluded from the evaluation of the other two indicators (number of ducks, number of geese and guinea fowls) because the provided information about them is for the period from 1994 to 2011.

Table 3 The results for the surveyed data on the number of geese and guinea fowls

\begin{tabular}{|c|l|l|}
\hline Countries & \multicolumn{2}{|l|}{$\begin{array}{l}\text { Assessment of the number } \\
\text { of geese and guinea fowls }\end{array}$} \\
\hline Romania & 3758 & a \\
\hline Greece & 377 & b \\
\hline Bulgaria & 45 & c \\
\hline
\end{tabular}

Means with the same letter are not significantly different.

Source: Own calculations on the basis of data from FAO, FAOSTAT

\section{CONCLUSION}

This paper presents the dependencies in the development of poultry farming in four Balkan countries (Bulgaria, Greece, Romania and Albania) in the period from 1961 to 2018. The examined information has been extracted from the website of the Food and Agriculture Organization of the United Nations. The obtained data on the poultry farming (chickens, ducks, geese and guinea fowls) have been stored in a separate Excel file. Subsequently, they have been processed and evaluated.

The results of the analysis showed the relevant periods in which a continuous growth, as well as a significant decline of the considered indicators was established for the four studied Balkan countries.

The statistical assessment of the number of chickens in the indicated countries formed three groups with statistically significant differences.

The evaluation of the other two indicators (number of ducks and number of geese and guinea fowls) for the studied three countries (Bulgaria, Greece and Romania) showed groups with significant differences. The data for Albania were excluded because they cover only the period 1994-2011.

\section{REFERENCES}

$F A O$, www.fao.org/faostat/en

$F A O$, http://www.fao.org/faostat/en/\#data/QA

$F A O$, www.fao.org/economic/ess/ess-home/ess -about/data-collection/en/

Georgieva V., N. Blagoeva, 2019, Analysis of the Tax Legislation Applicable in Taxing the Incomes of the Farmers as Natural Persons, Management and Education, vol. 15 (1), pp.115-120

Kostadinova N., 2017, Trends IN Restructuring of Bulgarian Agriculture, Trakia Journal of Sciences, Vol. 15, Suppl. 1, pp 167171, Available at: http://tru.uni- 
75 years of Agricultural University - Plovdiv JUBILEE SCIENTIFIC INTERNATIONAL CONFERENCE Plovdiv 26-28 November 2020

sz.bg/tsj/TJS_Suppl.1_Vol.15_2017/30.

pdf, [2020-10-12]

Levine D. M., D. F. Stephan, K. A. Szabat, 2016. Statistics for Managers Using Microsoft Excel, $8^{\text {th }}$ Edition, Pearson, USA

Lozanova, A., V. Krasteva, N. Blagoeva, 2001, The Influence of the Tax System on the Development of Agriculture, AUPlovdiv, Scientific works, vol. XLVI, book 5, pp. 169-174, [in Bulgarian].

Mathialagan P., Senthilkumar K., 2012. Extent of Awareness and Adoption of Disease Prevention and Control by Poultry Farmers. International Journal of Food, Agriculture and Veterinary Sciences. Vol. 2 (2). pp.1-4. ISSN: 2277-209X (Online)

Mihaylov. D., 2016. Excel 2013, New star, Sofia, [in Bulgarian].

Nguyen-Feng V., M. A. Stellmack, 2016. A Guide to Data Analysis in R Commander, University of Minnesota, https://manualzz.com/doc/28971240/aguide-to-data-analysis-in-r-commander-rcmdr-, [2020-07-16]

Sawyer S. F., 2009, Analysis of Variance: The Fundamental Concepts, The Journal of Manual \& Manipulative Therapy, volume 17, number 2, pp. E27- E38

Tukey J. W., 1949. Comparing Individual Means in the Analysis of Variance, International Biometric Society, Biometrics, Vol. 5, No. 2, pp. 99-114 